\section{Vrij wonen in}

\section{Vlaanderen}

AUTEURS Manten Devriendt \& Lomme Devriendt

FOTOGRAFIE Marco Wehe \& Yves Lorson

Architect Renaat Braem, een leerling van Le Corbusier, schreef: "Vanuit een vliegtuig moet België eruitzien als een door een krankzinnige bijeengenaaide lappendeken van bijeengeknoeid afval met daarop als door een woest geworden reus met verachting uitgestrooide blokkendozen."

Sinds zijn ontstaan heeft de mens zijn eigen wereld gebouwd. De gebouwde woonplaats varieert van uiterst gemeenschappelijk, meestal ter bevordering van de veiligheid, tot hoogst individueel, wanneer men zijn bescherming tracht te vrijwaren van invloeden van buitenaf. De keuze voor een bepaalde vestigingsvorm wordt in zekere mate gestuurd door leefstijl, die op zijn beurt weer afhangt van welvaart en macht. Hoe groter de welvaart of macht van een land of persoon, hoe meer men zich een eigen paradijs kan veroorloven. Bij de opkomst van de massamaatschappij ontstond een leefstijl die 'het wilde wonen' wordt genoemd. Mensen begonnen hun woning steeds meer te spiegelen aan hun bezit en toonden hun macht om dat bezit te beschermen. Hierdoor ontstond in Vlaanderen een mix van architectuurstijlen in een ongeorganiseerde landstedelijke woonomgeving. Dit artikel gaat in op deze typisch Vlaamse variant van Carel Weebers Wilde Wonen, die veel meer omvat dan de individualisering van het woningontwerp. Het wilde wonen is in Vlaanderen een suburbane levensstijl. De opkomst van deze wilde of vrije woonstijl - een villa met private tuin, liefst omringd door een metershoge beukenhaag, in een landelijke omgeving - wordt wellicht het best geillustreerd door de plotse verstedelijking van Vlaanderen vanaf de jaren zestig. De politiek ondersteunde dergelijke individuele planning op het platteland door kavels aan particulieren uit te geven. Uitbreidingen van het Vlaamse wegennet volgden op de groeiende behoefte aan bereikbaarheid door het steeds decentraler wordende vestigingspatroon.

Het wegenpatroon volgde de verstedelijking in plaats van haar te organiseren. leder dorpje kreeg een eigen op- en afrit op het toentertijd vlotte verkeersnet. Er werd een droomland voor de wagen gecreëerd, maar tegelijkertijd een nachtmerrie voor ophaaldiensten, openbaar vervoer en natuurbehoud. De klinkerwegen die de grote steden met elkaar verbonden, werden vervangen door brede (snel-) wegen, zodat koning auto zich sneller kon verplaatsen. Onder invloed van de planologische 'invulregel' om open stukjes grond langs wegen efficiënt te benutten, werden deze wegen steeds dichter omgeven met

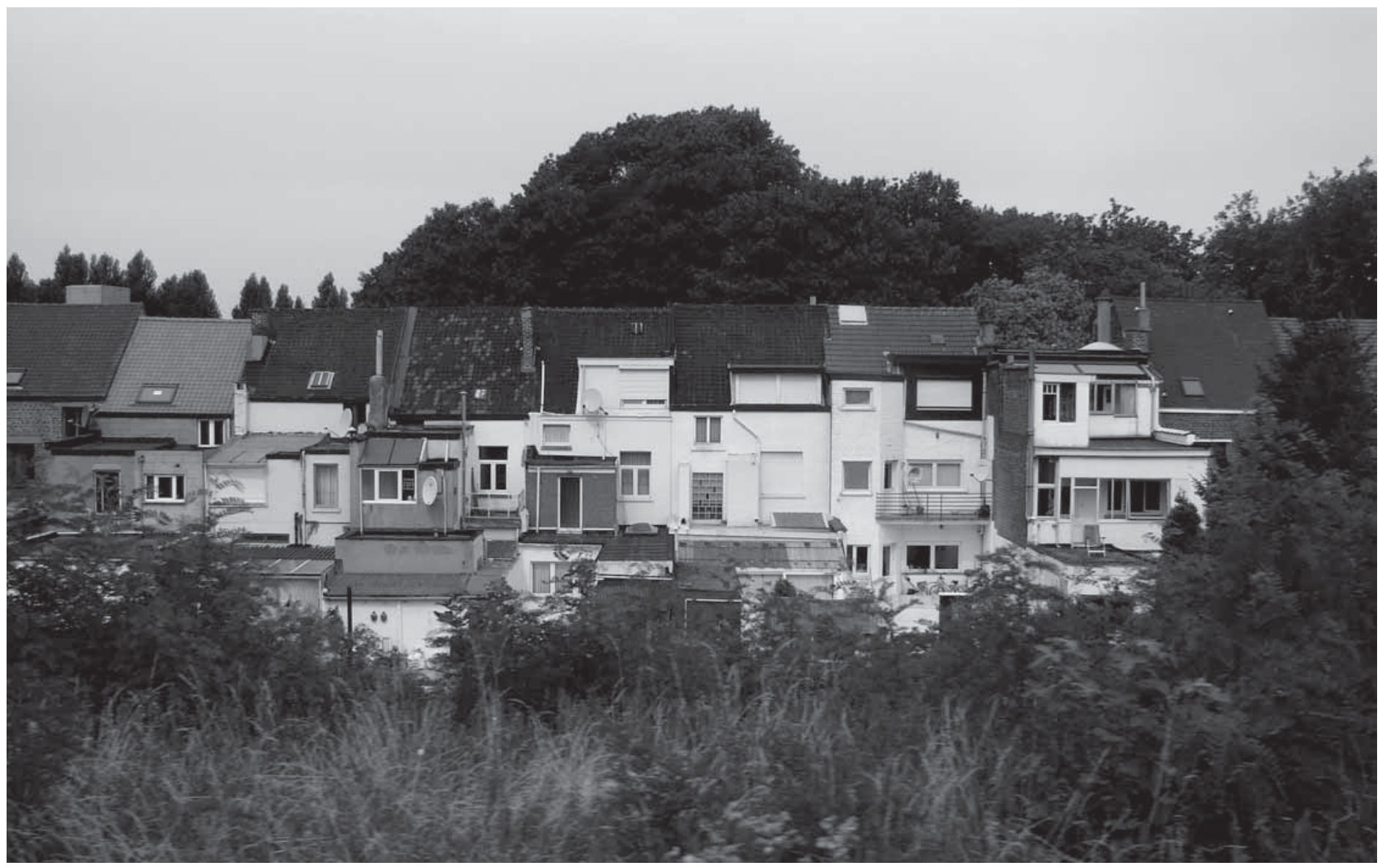


bebouwing en kregen op die manier een sterk gesloten karakter. Vanuit de oude gemeentekernen ontstonden bebouwingslinten, die tot op heden van stad tot stad en van dorp tot dorp lopen. Het Vlaamse platteland kreeg een stedelijk aanzien door een bonte mix van diverse rijtjeswoningen en decoratieve woonboerderijen, omgeven door zelf ontworpen schuurtjes, veranda's en dergelijke.

Het verschijnsel dat in dit artikel centraal staat, is de leefstijl van mensen die in suburbane gebieden hun eigen, vaak vrijstaande, huizen bouwen. Deze leefstijl wordt gestuurd door macht en welvaart. We onderscheiden het daarmee van het wilde wonen in sloppenwijken, waar praktisch geen organisatie waar te nemen is.

De wilde woonstijl is in Vlaanderen vaak onderwerp van discussie. J e kan je eraan ergeren en het tegenwerken, of het aanvaarden en erop voortbouwen. In Vlaanderen zijn we echter in een situatie beland waarin het eerste inmiddels geen optie meer is. De leefstijl van de wildwoner is wijdverspreid, en een starre topdownplanning biedt geen oplossing. De 'ongeorganiseerde' levensstijl moet men dus verder en vooral diepgaander onderzoeken. Hoe kan men aan de verlangens van bewoners voldoen en toch een georganiseerde planning nastreven? Dit artikel heeft tot doel een deze Vlaamse leefstijl te beschrijven en een richting aan te geven hoe in deze conditie verder kan worden gewerkt.

\section{Hoe kan men aan de 'wilde' wensen van bewoners vol- doen en toch georganiseerd plannen?}

\section{Het 'wilde' wonen}

Door zijn welvaart en macht over de omgeving kan de wildwoner zich een eigen paradijs veroorloven. Waar hij maar kan, zal hij proberen de grenzen van de regelgeving op te zoeken. Door wild wonen kan hij in de vormgeving en locatie van de woning zijn eigen smaak en leefstijl tonen. Geplande wijken bieden die persoonlijke vrijheid vaak niet. We spreken hier overigens niet van ongewenste ontwikkelingen. In Vlaanderen wordt dit proces voornamelijk gestuurd door de doe-hetzelfzaak en fabrikanten van cataloguswoningen.

Het wilde wonen ontwikkelde zich vooral in de laatste fase van het proces waarin urbanisatie, suburbanisatie en desurbanisatie elkaar opvolgden. In de middeleeuwse stad zorgde een fysieke afbakening voor een scheiding tussen stad en platteland. Toen deze grens verdween en er een onderscheid tussen stedelijk en landelijk ontstond, werd het wonen gecontroleerd door de stadsplanner. Wie op zoek is naar vrijheid, laat zich echter makkelijker tegenhouden door een muur dan door een lijn. De ruimte buiten de denkbeeldige stadsgrens werd steeds meer als potentiële woonplaats gezien, ook doordat men daar gemakkelijk een bouwkavel kon kopen. Daar kon men genieten van groen en open ruimte, waarvoor ondertussen in de dichtbevolkte stad geen plaats meer was. De technologische ontwikkeling zorgde er bovendien voor dat men steeds meer mogelijkheden kreeg om zijn eigen bouwsel te maken.

De suburbane ruimte spreidde zich aldus steeds verder uit, en het gevolg is bekend: van open gebied is in Vlaanderen momenteel geen sprake meer. Dit proces wordt desurbanisatie genoemd, de situatie waarin alle ruimte stad wordt. De stadsrand vormde tijdens het suburbanisatieproces de eerste drempel naar het wonen in open gebied. Door de daaropvolgende desurbanisatie ontstond het stedelijk veld Vlaanderen. O nder een stedelijk veld verstaat men een uitgespreide archipelstructuur waartoe ook de open gebieden van het vroegere landelijke gebied behoren. Dit stedelijk veld bekoort het ultieme wilde wonen: volledige vrijheid en keuze in de manier van wonen.

De bewoner die vroeger gedwongen werd in de dichtbevolkte stad te leven, kan nu zijn eigen deel van het platteland koloniseren. Met de auto verplaatst hij zich vlot naar stedelijke activiteiten en 's avonds geniet hij met de kinderen van een barbecue in zijn uitgestrekte tuin met zicht op de eigen villa. Filoso of Lieven de Cauter ziet in dit patroon de cocoonmaatschappij verschijnen: de stedelijke gemeenschap verdwijnt en in plaats daarvan ontstaat een uitgesmeerd veld van individuen.

Parallel met de voortschrijding van het individualiseringsproces ontstaan nieuwe deelmarkten en marketingvormen die zich nadrukkelijk op de zelfbewuste individuele consument richten, ook binnen de woningmarkt. De neoliberale systemen ondersteunen het marktprincipe dat de koper mogelijkheden biedt en hem het gevoel geeft eigen keuzes te maken. De markt levert niet langer een van bovenaf bedachte woningbouw, maar een grote individuele keuzevrijheid in woningtypologieën en woonlocaties die door de klant vrij kunnen worden benut. Wonen met de voordeur in de grote stad met alle faciliteiten en met de achterdeur in de vrije natuur: het is de droom geworden van iedere welgestelde burger. Dit zorgde in Vlaanderen voor een verstedelijking van het landelijk gebied. Vandaar dat we liever van een stedelijk veld dan van een landelijk of stedelijk gebied spreken.

Het invullen van het open gebied vraagt echter andere planning met meer aandacht voor stedelijkheid. Indien men de conditie van wild wonen aanvaardt, zal hier rekening mee gehouden moeten worden. De planner heeft immers de maatschappelijke taak om de publieke ruimte te beschermen.

\section{Openbare ruimtes en voor- zieningen ontbreken doordat de wildwoner alleen voor zichzelf bouwt.}

\section{Inspelen op wild wonen}

De wildwoner wil dus gebruikmaken van de stedelijke faciliteiten, genieten van de eigenschappen van het landelijke wonen en liefst zonder al te veel regelgeving met eigen middelen bouwen. Het ontwikkelen van zo'n systeem is kostbaar, en het is dan ook een verstedelijkingspatroon van een land waar het goed mee gaat. Het ophalen van vuilnis, communicatie-infrastructuur en openbaar transport vormen moeilijkheden in dit bebouwingspatroon. Doordat de wildwoner alleen voor zichzelf bouwt, ontbreken de voor de stad kenmerkende openbare voorzieningen. 


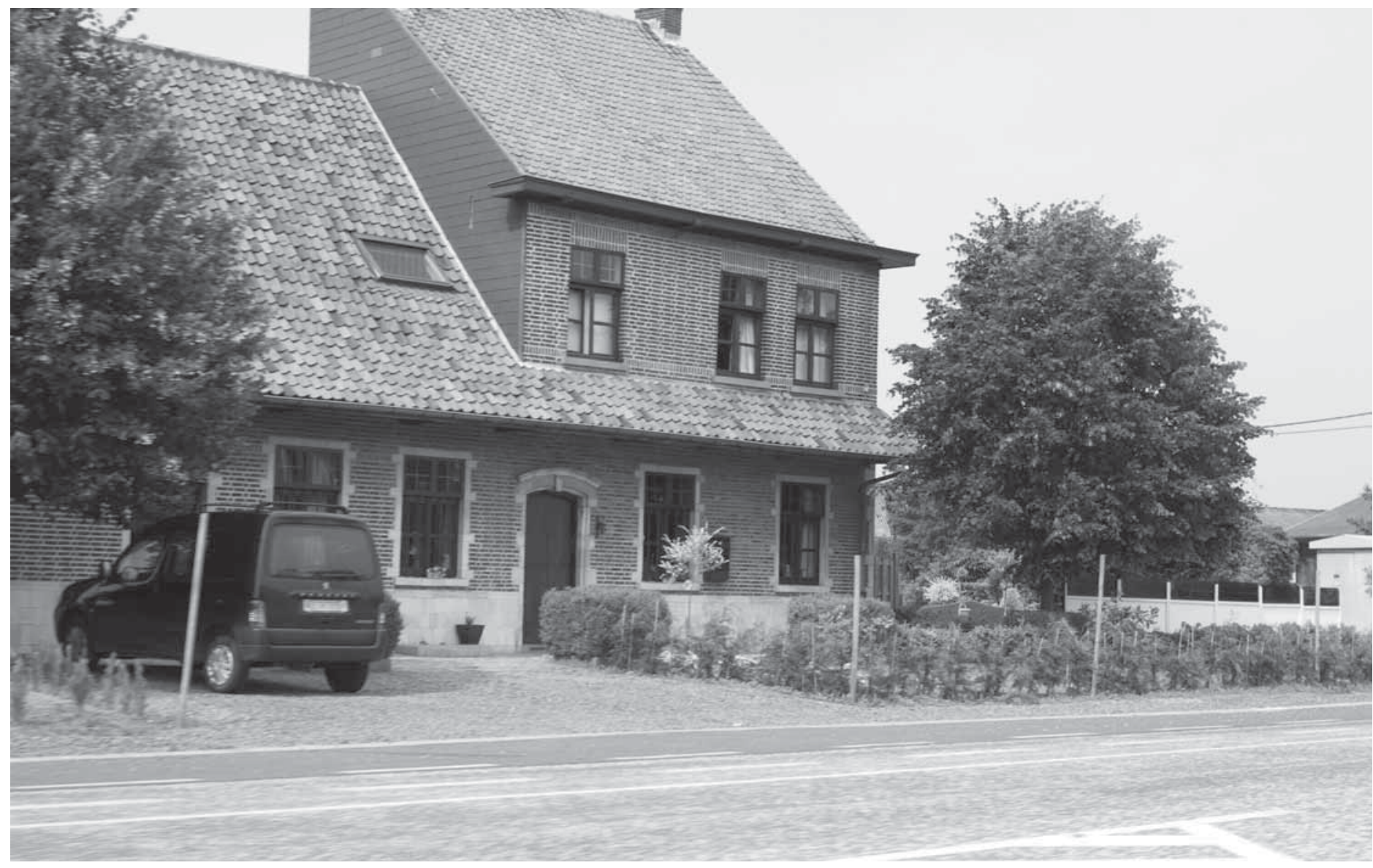

De grootste opgave voor het ontwerp van de wilde of vrije woonstructuur is hoe je openbare ruimte kunt toevoegen aan het stedelijke veld. Als we het stedelijke veld goed observeren, ontdekken we er een rijk palet aan nieuwe soorten openbare ruimtes. Voormalige zandputten bijvoorbeeld, die werden ontgonnen voor de aanleg van snelwegen, zijn openbare ruimtes geworden in de verspreide stad. Het zijn nu grote waterplassen en plekken bij uitstek om 's zondags te ontspannen of wekelijks te joggen.

Participatie van de bewoners is in alle planvormen van het wilde wonen belangrijk om het gebruik van deze openbare ruimtes succesvol te maken. De wildwoner gaat immers op zoek naar een bouwterrein, dat hem hoe dan ook wordt aangeboden door een verkoper, waar hij al dan niet met hulp probeert zijn eigen woning te realiseren. Schijnbaar goedkoper - want de prijs hangt af van zijn eigen beslissingen - kan hij zich zodoende onttrekken aan de vooraf geplande woning. Dit gegeven zou de stadsplanner wakker moeten schudden en inspireren om met de bewoners mee te denken.

In de jaren zeventig stond het participatiemodel bij planners hoog op de agenda, maar dit lijkt men te zijn vergeten. Het principe dat bewoners actief meeontwerpen is vandaag de dag vervallen tot eindeloos discussiëren zonder resultaat voor de bewoner. Door stapsgewijs acties te ondernemen zou participatie veel meer resultaat kunnen opleveren dan het streven van planners naar een algemeen stedenbouwkundig eindproduct. De woonmarkt heeft dit wel begrepen en biedt wildwoners concrete elementen waarmee zij hun creativiteit kunnen uitleven. Dit leidt in de ogen van veel architecten en stedenbouwkundigen wellicht tot wansmakelijke producten, maar de doeltreffendheid van de methode kan alleen maar bewondering afdwingen.
In Vlaanderen wordt het planningsritme vandaag de dag door de markt bepaald. De grote fabrikanten van cataloguswoningen hebben planners in dienst die op het randje van de huidige wetgeving gebieden klaarmaken voor het wilde wonen. Bij de ontwikkelaars staat de participatie van bewoners steeds voorop, zodat verschillende leefstijlen hun gading kunnen vinden binnen een algemeen stedenbouwkundig ontwerp. Ontwikkelaars negeren daarbij echter wel de opdracht om openbare ruimtes te maken, en daar ligt dan ook een taak voor stedenbouwkundigen.

Door gevat op dit proces in te spelen kan de stedenbouw samen met alle belanghebbenden kwalitatief goede openbare ruimte generen. Als men de conditie van het wilde wonen aanvaardt, is dit van het grootste belang, omdat het de nieuwe bebouwing de nodige ademruimte geeft. Zoals de architect grootmeester Le Corbusier met zijn 'modular' een perfecte verhouding zocht om de menselijke ruimte te ontwerpen, zo heeft ook het stedelijk veld ademruimte nodig om de burger een gezond leven te kunnen bieden.

De Vlaamse lintbebouwing heeft een zekere radius nodig waarin open ruimte aanwezig is om nog als open gebied beschouwd te kunnen worden. Zo kan men een gebied met linten benutten zonder het gevoel te hebben dat de ruimte verzadigd is. Daarnaast moet men leren omgaan met de echte noden van een hedendaagse landstedelijke ruimte, zoals het verkeers- en vervoersprobleem. Onder invloed van een sterke economie is het open veld in Vlaanderen sterk verstedelijkt. Had men de golf van verstedelijking gepaard laten gaan met de aanleg van enkele stedelijke elementen, dan was het nu veel makkelijker geweest om in het huidige systeem te werken. ledere goedwerkende stad heeft een vlot openbaar verkeerssysteem. In 
een stedelijk veld kan een dergelijk systeem ook worden uitgewerkt. Het Amerikaanse planningsparadigma N ew Urbanism, waarin via de vormgeving van suburbane gebieden getracht wordt de sociale cohesie en een duurzame leefomgeving te bevorderen, heeft veel sneller gecontroleerd op dit idee van wonen ingespeeld. We beweren overigens niet dat dit de optimale aanpak voor het stedelijke veld is. Wij sturen eerder aan op een scenariogerichte planning. In tegenstelling tot traditionele planning richt scenarioplanning zich niet op een vastomlijnd eindbeeld, maar vormen onzekerheden het uitgangspunt voor mogelijke scenario's. De scenario's geven de verschillende richtingen aan waarin het stedelijke veld zich kan ontwikkelen. Afhankelijk van het belang van verschillende groepen evolueert een gebied dan in een bepaalde richting. Scenarioplanning legt verschillende parameters bloot waarop ontwikkelaars zich kunnen richten bij het nemen van beslissingen en het voorzien van grote delen stedelijk gebied van de nodige openbare ruimte. Wij zien scenario's die een stedelijke aanpak voor het stedelijke veld vooropstellen als een methode om de planning in Vlaanderen in goede banen te leiden.

De wilde woonstijl in Vlaanderen biedt tal van mogelijkheden die zowel de verlangens van de stedenbouwkundige planner, de architect, als de bewoners kunnen vervullen. Stedenbouw moet dan echter niet een discipline blijven van de lange duur en een vastomlijnd eindresultaat, maar eerst en vooral op korte termijn aan creativiteit en flexibiliteit winnen. We weten hoe we in de stad moeten plannen. We weten ook hoe we in het landelijk gebied moeten plannen. Maar wat te doen met dit verstedelijkte landschap? We zullen het stedelijke veld meer en meer moeten gaan beschouwen als stad. Steden krijgen vorm door pleinen en straten, en ook stedelijke velden hebben openbare ruimtes nodig. Het stedenbouwkundige antwoord op de conditie van het wilde wonen is daarom flexibele scenarioplanning, waarin ruimte is voor bewonersparticipatie en die zich richt op het ontwerp van openbare ruimtes die passen bij de leefstijlen in het Vlaamse stedelijke veld.

Manten Devriendt (info@pecha-kucha.Iv) is gediplomeerd stedenbouwkundige en Ingenieur-architect. Manten is tevens oprichter van Pecha Kucha Riga <www.pecha-kucha.Iv>, een forum voor jonge ontwerpers en architecten. Lomme Devriendt (lomme.devriendt@ugent.be) is Aspirant van het FWO-Vlaanderen aan de Universiteit Gent, departement Geografie, en redacteur van AGORA.

\section{Literatuurselectie}

Braem, R. (1968) Belgie, het lelijkste land ter wereld. Horizonreeks Davidsfonds dl. 9. Leuven: Davidsfonds.

Huxley, A. (1998) Brave new world. New York: HarperCollins Publishers.

Laermans, R. (2002) Stedelijkheid in de veralgemeende moderniteit.

Positiepaper. Centrum voor Cultuursociologie, KULeuven. 